Results: Data were available on 54284 subjects (52\% female). During follow-up (median 21 years), 283 women and 110 men developed RA. The median (IQR) time to onset of RA was 7 (4-11) years. The adjusted hazard ratio's (HR) for developing RA are presented in Table 1. Restricted cubic spline analysis of body fat percentage displayed a positive slope in women (Image). There was no linear association between amount of fat and incidence of RA among men.

Conclusions: Overweight and obesity, defined by BMI, abdominal obesity and higher body fat percentage, especially above $30 \%$, were in women associated with a higher risk for the development of RA. In men the associations were not consistent.

Acknowledgements: The Danish Rheumatism Association, The Danish Heart Foundation, Central Denmark Region, North Denmark Regional Hospital, Scandinavian Rheumatology Research Foundation

Disclosure of Interest: None declared

DOI: 10.1136/annrheumdis-2017-eular.1526

\section{OP0080 RISK OF AUTISM SPECTRUM DISORDER IN CHILDREN BORN TO MOTHERS WITH SYSTEMIC LUPUS ERYTHEMATOSUS AND RHEUMATOID ARTHRITIS IN TAIWAN}

P.-H. Tsai, C.-F. Kuo, L.-H. Huang, S.-F. Luo. Division of Rheumatology, Allergy and Immunology, Chang Gung Memorial Hospital, Taoyuan, Taiwan, Province of China

Background: There is emerging evidence suggesting that offspring born to patients with rheumatic diseases has higher risk of neuropsychiatric diseases. Previous data from Quebec showed children born to women with SLE have an increased risk of autism spectrum disorder (ASD) but data regarding risk of ASD in offspring of mothers with systemic lupus erythematosus (SLE) or rheumatoid arthritis (RA) mothers have not been reported in other population.

Objectives: We aimed to examine whether offspring of mothers with SLE and RA in Taiwan has a higher risk of developing ASD using data from a linkage between National Health Insurance (NHI) database and National Birth Registry in Taiwan. Methods: We established a birth cohort of all live-births between 2001 and 2012 in Taiwan established using the National Health Insurance database and the National Birth Registry. Children born to mothers with SLE or RA were identified and matched up to 8 controls by maternal age, 1-minute Apgar score, 5-minute Apgar score, mode of delivery, sex of child, gestational age, birth weight, socioeconomic status (place of residence, income level, occupation). A marginal Cox proportional hazard models were used to estimate the relative risk (RR; $95 \%$ confidence interval $[\mathrm{Cl}]$ ) for ASD in newborns with affected mothers.

Results: Of $1,893,244$ newborns, $0.08 \%(n=1,594)$ were born to mothers with SLE (mean age $30.43 \pm 4.37$ years old) and $0.04 \%(n=673)$ were born to mothers with RA ( $31.97 \pm 4.51$ years old). Overall, 5 of $673(0.74 \%)$ RA offspring developed ASD, 7 of $1594(0.44 \%)$ SLE offspring developed ASD and 10,631 of 1,893,244 $(0.56 \%)$ all infants developed ASD. The incidence of ASD was $140.39(95 \% \mathrm{Cl}$, 45.58-327.62) per 100,000 person-years for RA group, 76.19 (95\% Cl, 30.63156.97) per 100,000 person-years for SLE group, 89.85 (95\% Cl, 88.15-91.57) per 100,000 person-years for non-RA group and 89.87 (95\% Cl, 88.17-91.60) per 100,000 person-years for non-SLE group. The children born to RA and SLE mothers did not have higher risk of ASD with a HR $(95 \% \mathrm{Cl})$ of $1.42(0.60-3.40)$ and $0.76(0.36-1.59)$ for ASD, respectively.

Conclusions: Children born to women with SLE and RA do not have higher risk of developing ASD.

References:

[1] Lahita, R.G., Systemic lupus erythematosus: learning disability in the male offspring of female patients and relationship to laterality. Psychoneuroendocrinology, 1988. 13(5): p. 385-96.

[2] Vinet, E., et al., Increased Risk of Autism Spectrum Disorders in Children Born to Women With Systemic Lupus Erythematosus: Results From a Large Population-Based Cohort. Arthritis Rheumatol, 2015. 67(12): p. 3201-8.

Disclosure of Interest: None declared

DOI: 10.1136/annrheumdis-2017-eular.2882

\section{WEDNESDAY, 14 JUNE 2017}

\section{Scleroderma, myositis and related ethology}

\section{OP0081 PAN-PPAR AGONIST IVA337 IS EFFECTIVE IN THE PREVENTION OF EXPERIMENTAL LUNG FIBROSIS AND PULMONARY HYPERTENSION}

J. Avouac ${ }^{1}$, I. Konstantinova ${ }^{2}$, C. Guignabert ${ }^{3}$, J. Sadoine ${ }^{4}$, G. Thomas $^{5}$ S. Pezet ${ }^{5}$, A. Cauvet ${ }^{5}$, L. Tu ${ }^{3}$, J.M. Luccarini ${ }^{2}$, J.L. Junien ${ }^{2}$, P. Broqua ${ }^{2}$, Y. Allanore ${ }^{1} .{ }^{1}$ Rheumatology $A$ and INSERMU1016, Paris Descartes University, Cochin Hospital, Paris; ${ }^{2}$ Inventiva, Daix; ${ }^{3}$ INSERM UMR s 999, le Plessis Robinson; ${ }^{4}$ Université Paris Descartes, Montrouge; ${ }^{5}$ INSERM U1016, Paris, France

Background: Peroxisome proliferator-activated receptors (PPARs) are nuclear receptors known to modulate fibrosis. The pan-PPAR agonist IVA337 recently demonstrated efficacy in prevention and treatment of experimental skin fibrosis [1].
Objectives: Our objective was to evaluate the antifibrotic effects of IVA337 in preclinical mouse models of pulmonary fibrosis and related pulmonary hypertension $(\mathrm{PH})$.

Methods: IVA337 has been evaluated in the mouse model of bleomycin-induced pulmonary fibrosis and in Fra-2 transgenic mice, this latter being characterized by non-specific interstitial pneumonia and severe vascular remodeling of pulmonary arteries leading to PH. Mice received 2 doses of IVA337 (30 mg/kg or $100 \mathrm{mg} / \mathrm{kg}$ ) or vehicle administered by daily oral gavage up to 4 weeks.

Results: Both $30 \mathrm{mg} / \mathrm{kg}$ and $100 \mathrm{mg} / \mathrm{kg}$ doses of IVA337 were well tolerated in all mouse models.

IVA337 demonstrated at a dose of $100 \mathrm{mg} / \mathrm{kg}$ a marked protection from the development of lung fibrosis induced by bleomycin compared to mice receiving $30 \mathrm{mg} / \mathrm{kg}$ of IVA337 or vehicle. Indeed, IVA337 (100 mg/kg) strongly reduced by $61 \%$ and $28 \%$ tissue density on histological measurements and total lung hydroxyproline concentrations, respectively, as compared to vehicle. IVA337 at $100 \mathrm{mg} / \mathrm{kg}$ also significantly decreased col1, col3 and fibronectin in lesional lungs. Similarly, Fra-2 transgenic mice treated with $100 \mathrm{mg} / \mathrm{kg}$ of IVA337 displayed reduced lung density ( $20 \%$ vs. vehicle) and significant increase of functional residual capacity ( $30 \%$ vs. vehicle) when assessed by chest micro-CT imaging. These results were emphasized by a $50 \%$ reduction of the Ascroft fibrosis score (Figure $1 \mathrm{~A}$ ) and by a $48 \%$ reduction of hydroxyproline concentrations upon IVA337 $(100 \mathrm{mg} / \mathrm{kg})$ compared to vehicle treated mice.

Successful targeting of the TGF-b signaling axis was observed in both mouse models upon treatment with $100 \mathrm{mg} / \mathrm{kg}$ of IVA337. $100 \mathrm{mg} / \mathrm{kg}$ IVA337 also significantly reduced $T$ cell and $B$ cell infiltration in lesional lungs of Fra-2 transgenic mice.

Regarding vessel remodeling and related pulmonary hypertension, treatment with $100 \mathrm{mg} / \mathrm{kg}$ of IVA337 led to a substantial attenuation of right ventricular systolic pressure and right ventricular hypertrophy compared to mice receiving the vehicle (Figure 1B and $1 \mathrm{C}$ ). Furthermore, IVA337 given at $100 \mathrm{mg} / \mathrm{kg}$ markedly reduced medial wall thickness (Figure 1D) and the number of muscularized distal pulmonary arteries.

In vitro in primary human lung fibroblasts, IVA337 inhibited in a dose-dependent manner TGF $\beta$-mediated fibroblasts to myofibroblasts transition and PDGFmediated proliferation.

A
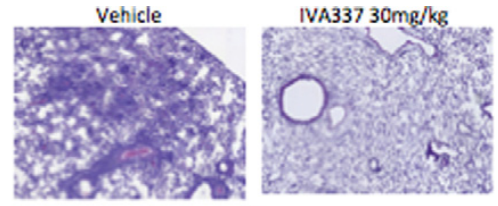
IVA337 $100 \mathrm{mg} / \mathrm{kg}$

B
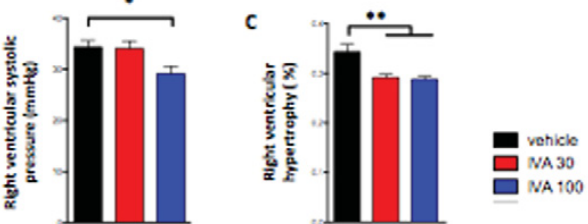
Vehicle IVA337 $30 \mathrm{mg} / \mathrm{kg}$ IVA337 $100 \mathrm{mg} / \mathrm{kg}$

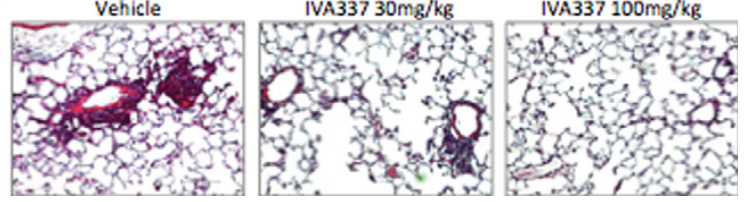

Figure 1

Conclusions: We demonstrate that treatment with $100 \mathrm{mg} / \mathrm{kg}$ IVA337 prevents lung fibrosis in two complementary animal models and substantially attenuates $\mathrm{PH}$ in the Fra-2 mouse model. These findings confirm that the pan-PPAR agonist IVA337 is an appealing therapeutic candidate for systemic sclerosis both, for skin and key cardiovascular complications.

References:

[1] Ruzehaji et al, Ann Rheum Dis 2016;75(12):2175-2183.

Disclosure of Interest: J. Avouac: None declared, I. Konstantinova Employee of: INVENTIVA, C. Guignabert: None declared, J. Sadoine: None declared, G. Thomas: None declared, S. Pezet: None declared, A. Cauvet: None declared, L. Tu: None declared, J. M. Luccarini Employee of: INVENTIVA, J. L. Junien Consultant for: INVENTIVA, P. Broqua Employee of: INVENTIVA, Y. Allanore

Grant/research support from: Inventiva

DOI: 10.1136/annrheumdis-2017-eular.3805 